\title{
The Complexity of the Homeopathic Healing Response Part 1: The Role of the Body as a Complex Adaptive System in Simillimum-Initiated Recovery from Disease
}

\author{
Iris R. Bell ${ }^{1}$ \\ ${ }^{1}$ Department of Family and Community Medicine, The University of \\ Arizona College of Medicine, Tucson, Arizona, United States \\ Homeopathy 2020;109:42-50.
}

Address for correspondence Iris Bell, MD, PhD, 10645 North Oracle Road, Suite 121-126, Tucson, AZ 85737, United States (e-mail: ibell@email.arizona.edu).

\begin{abstract}
Keywords

- homeopathy

- self-organization

- complex adaptive systems

- biological signaling networks

- self-similarity
\end{abstract}

Background The concepts of complex systems science enhance the understanding of how people develop and recover from disease. Living systems (human beings, animals, and plants) are self-organizing complex adaptive systems (CAS): that is, interconnected networks. CAS maintain life by initiating and carrying out non-linear dynamical changes to optimize survival fitness and function in the context of an ever-changing environment.

Aims In Part 1 of this two-part paper, we relate concepts from complex systems science to homeopathic healing. The systemic changes of homeopathic healing involve adaptive patterns of responses to salient signals (similia) for reversing disease patterns and generating emergent multi-symptom healing over time.

Methods and Results This narrative review relates homeopathic clinical practice theory to complex systems and network research. Homeopathic medicines communicate individually salient environmental information to the organism, with effects that are multi-system and indirect. The body's defense mechanisms recognize the self-similar information that the correctly chosen simillimum medicine at low dose conveys as a weak external/internal environmental stressor or danger signal (hormetin) to mobilize neural and cellular defenses. The body networks then use endogenous cell to cell signaling and amplify the small magnitude signal information. The results are disproportionately large: that is, non-linear, adaptive, modifications across the inter-connected self-organized biological networks/subsystems of the body. CAS amplification mechanisms for small or weak signals include stochastic resonance, time-dependent sensitization, and hormesis.

Conclusions The body as a complex system has the capacity for self-organization, emergence and self-similarity over global (overall health and wellbeing) and local (organ) levels of organization. These features are key for future research on the systemic healing that evolves over time during individualized homeopathic treatment.

\section{Introduction}

This two-part paper focuses on the integrative model for the complex, self-organizing nature of both (1) recipient living systems $^{1-4}$ and (2) homeopathic medicines ${ }^{5-10}$ as the basis for homeopathic healing. In Part 1, we review how complex

received

April 16, 2019

accepted after revision

June 21, 2019

published online

November 30, 2019

systems science applies to homeopathic clinical concepts and the non-linear, system-wide healing response that simillimum treatment initiates.

Homeopathy is historically one of several whole systems of care in complementary and alternative medicine (CAM).${ }^{11-14}$ Classical homeopathy focuses on treating the

Copyright @ $\odot 2020$ The Faculty of Homeopathy
DOI https://doi.org/ 10.1055/s-0039-1694998. ISSN $1475-4916$. 
patient as an indivisible whole (living system). ${ }^{11-13}$ For homeopathy, the "diagnosis" is determination of the one medicine that best matches (is most similar to) the whole, integrated, bio-psychosocial symptom picture or pattern (state) of the patient at the time of treatment.

As a whole system of CAM, classical homeopathy requires one unified diagnosis (the medicine picture [state of the patient] in the present time), and treatment with the single medicine treatment that best captures the information pattern of a similar, multi-subsystem pattern of symptoms. Homeopathic symptoms are manifestations of a singular, pervasive, emergent disturbance of the state of the individual as a whole system or network of networks, not of a specific body part or biological mechanism in isolation.

Homeopathic clinical practice theory provides a framework for understanding and studying the whole-system nature of homeopathic healing from disease. In fact, clinical practice theory steers research thinking toward the modern science of complex systems (complexity). ${ }^{1-3,12,15-20}$ Complexity science involves the study of systems that comprise many separate but inter-connected, inter-dependent, and interactive parts.

\section{Complexity, Complex Systems, and Networks}

Complex adaptive systems (CAS) are living systems or networks adapting and optimizing their fitness to survive over time within the context of an ever-changing environment. In a complex adaptive system, the global, that is, emergent, whole is greater than the sum of the parts (- Table 1). 1,2,15,21-27

From a complexity perspective, changes in the external and/or internal environment trigger interactive non-linear dynamical adaptive changes in a biological system across different levels of self-organized scale. Change in one part leads to change in other parts because of the network physiological and biochemical linkages between the parts. ${ }^{28}$ Disease evolves over time when the "adaptive" changes to environmental stressors lead to undesirable alterations in functional set-points and emergence of disease symptoms. ${ }^{26}$ The body is doing the best it can to cope with and survive the

Table 1 Complex adaptive system at different levels of selforganized scale

\begin{tabular}{|l|l|}
\hline Parts & Emergents \\
\hline Genes & Cells \\
\hline Cells & Organs \\
\hline Organs & Body network functions \\
\hline Organisms & Individual behaviors \\
\hline Groups, societies & Social behaviors \\
\hline $\begin{array}{l}\text { Chemical, biological, } \\
\text { physical Environments }\end{array}$ & Planetary ecosystem \\
\hline
\end{tabular}

Note: Non-linear dynamical adaptive interactions of the parts at a given level of organizational scale generate collective properties that in turn emerge at the next level of organizational scale (e.g., cells to organs to organism to behavior of the organism within its environment).

[Content is original to the author] impact of its surrounding adverse bio-psychosocial and/or physical environmental stressors/conditions.

At different levels of scale, patterns of weather, societies, individual organisms (e.g., a human body or a yeast cell's biochemical network), ${ }^{28}$ an organ, or a mammalian cell each reflect their inherent nature as a type of complex adaptive system at a particular level of organizational scale $25,28,29$. - Table 1 lists self-organizing CAS at different levels of organizational scale, as well as their emergents (collective properties). Self-organization is a hallmark feature of CAS. ${ }^{25,30}$

Several key clinical observations reveal the importance of a complexity model for homeopathic healing. These observations include:

(a) the diagnostic goal of identifying patterns of symptoms, not an isolated symptom, to match to the individually correct medicine symptom picture (simillimum): for example, generalities such as location, quality, timing, pace of the clinical course, improvement or worsening under specific environmental conditions such as temperature, weather, altitude (overall, patterns of system behavior across different levels of organizational scale-sensitivity to initial conditions; self-similarity-see - Table 2);

(b) observing the ability of an individually salient, quantitatively low, dose of the correct medicine (simillimum) to trigger disproportionately large-magnitude system-wide reversal of multiple symptoms (disease) (non-linearity; self-organized criticality; emergence-see -Table 2);

(c) noting systemic change in healing that follows a selforganized hierarchical course from above downward, inside out, from more important to less important organs, and in reverse order of time of symptom appearance: that is, Hering's Law of Cure ${ }^{31}$ (self-organizationsee-Table 2). Symptom suppression by conventional drugs, in contrast, prevents disease manifestation at a less important organ and redirects the disease process back to more important organs within the body network.

- Table 2 lists properties of CAS. Among the properties is self-similarity across multiple levels of organizational scale. This property can be structural and/or temporal in nature. - Figure 1 illustrates an example of a natural complex system in which the sub-unit structure resembles the structure of the whole unit: for example, a snowflake. As a snowflake forms, cold water freezes on to dust particles and self-organizes into a repeating pattern of structural growth from its smallest component part to its overall global ice crystal shape. Physiological functions can take on temporal self-similarity in their emergent signals: for example, electroencephalography (EEG), heart rate beat-to-beat variability.

In the present model, once initiated, the adaptive changes evolve over time across the biological network that is the body, without requiring continued presence of a medicine or drug in the body. Emergent properties, that is, altered system behaviors (e.g., symptom patterns [system behavior]), are one feature of any complex adaptive system. ${ }^{1-3,15,17,18}$ The parts of a living system are in continuous interaction with one another and with the emergent global whole over time. $^{32}$ 
Table 2 Properties and definitions in complex adaptive systems (CAS) science ${ }^{13,25,32,33}$ [Content is original to the author]

\begin{tabular}{|c|c|}
\hline Property & Definition \\
\hline $\begin{array}{l}\text { Sensitivity to initial } \\
\text { conditions }\end{array}$ & $\begin{array}{l}\text { State-dependency in which the nature and direction of change depend on the initial conditions of the } \\
\text { complex system (including but not limited to past history) at the time of an environmental change that } \\
\text { evokes adaptation. } 27\end{array}$ \\
\hline Emergence & The properties (behaviors) of the global whole are greater than the sum of the parts of the system. ${ }^{25}$ \\
\hline Self-organization & $\begin{array}{l}\text { A process whereby local interactions between parts lead to spontaneous order patterns of the larger } \\
\text { whole (global) open system. There is no external hierarchical or controlling agent that predetermines the } \\
\text { emergent order. } 28,30,40\end{array}$ \\
\hline $\begin{array}{l}\text { Self-organized } \\
\text { criticality }\end{array}$ & $\begin{array}{l}\text { A property of far-from-equilibrium, non-linear, dynamical systems (such as the brain) in which the system } \\
\text { attains a critical state and spontaneously shifts into a new state space (attractor) with self-similar } \\
\text { behavior patterns in space and/or time. Examples in nature include avalanches and landslides. } \\
\text { Homeopathic healing may involve this type of shift in the body. }\end{array}$ \\
\hline $\begin{array}{l}\text { Adaptive ability } \\
\text { (evolution) }\end{array}$ & $\begin{array}{l}\text { Capacity to change the functioning and linkages within the system/network itself to optimize its fitness in } \\
\text { interaction with changes in its environment over time. } 25,28\end{array}$ \\
\hline $\begin{array}{l}\text { Self-similarity (frac- } \\
\text { tality--Fig. 1) }\end{array}$ & $\begin{array}{l}\text { Similarity of geometric structure (spatial) or processes in time (temporal) at every level of scale as in a shape } \\
\text { or a signal (e.g., a shape comprising parts that are similar to the whole-in nature, a snowflake, a } \\
\text { landscape, a bronchial tree; a physiological signal such as an electroencephalogram or heart rate } \\
\text { variability)-also observed in chaotic phenomena such as crystal growth and fluid turbulence: patterns or } \\
\text { images of dynamic systems in space and time. }{ }^{2,17,21,45} \\
\text { Clinically, consider a Bryonia patient with self-similar modalities for symptoms throughout the body, such } \\
\text { as worse from movement during ankle pain from a sprain or from coughing during a flu; or consider an } \\
\text { Aconite patient with sudden violent fear or sudden violent headache. Researchers also use fractal } \\
\text { dimension and related analyses to quantify complexity of physiological signals }{ }^{17,41} \text { as well as examine } \\
\text { blood samples of patients with specific diseases. } 103\end{array}$ \\
\hline $\begin{array}{l}\text { Non-linear dynam- } \\
\text { ical system }\end{array}$ & $\begin{array}{l}\text { CAS function as non-linear dynamical systems. Non-linear means that small changes in inputs can lead to } \\
\text { disproportionately large changes in system outputs. Dynamical is a term for the role of time and timing in } \\
\text { the relationship between inputs and outputs of a system. }\end{array}$ \\
\hline
\end{tabular}

Another relevant fact is that the medicine sources in classical homeopathy are typically natural plants (e.g., herbal), animals, and/or mineral materials. As such, the medicine information derives from what Csermely et al term "multitarget drugs" in the research literature on complex networks and health. ${ }^{33,34}$ That is, the simillimum medicine as a complex natural product can induce multiple changes in different directions at multiple different levels of the body networks, involving a variety of biological mechanisms.

In a complex system such as the human body, a multisymptom response evolves over time across multiple biological sub-systems or sub-networks (different levels of organizational scale) as the interactive information flows from different parts of the overall network change. As in homeopathic practice, the CAS response depends on the initial state of the recipient organism and then evolves over time. ${ }^{35}$ Consequently, the emergent outcomes are indirect rather than direct results of homeopathic simillimum treatment.

A classical homeopath selects each medicine with similar properties to best match the current symptom pattern of an individual patient, rather than a given symptom in isolation. Classical homeopathy thus treats disease as an emergent behavior pattern of the individual patient as an indivisible complex adaptive system, not as isolated local symptom mechanisms. In contrast, most conventional drugs typically target only one specific receptor type, thereby suppressing specific symptoms without treating the person as an integrated whole system/network.

\section{Applying Complexity Concepts to Health and Disease}

CAS include inter-dependent, inter-connected, and interactive parts at lower levels of organizational scale that signal and modulate each other's activity, as well as collective$1 y^{22,32,36-38}$ generate an emergent global whole in a nonlinear manner. In turn, the emergent global whole modulates function at the parts. - Figure $\mathbf{2}$ illustrates the ways in which the information flows both in and out of, as well as within, a CAS. "Parts" can be physical structures such as organs in a body or different mediators and signaling molecules in biochemical pathway networks.

The global level of scale within the system interacts with and modulates the functioning of the parts (where each part is a semi-autonomous agent: for example, an organ or a biochemical pathway). As noted above, in a complex system, the whole is greater than the sum of the parts (emergence).

Thus, the living body is a complex adaptive system evolving over time for optimal functional fitness to survive as it interacts with constant changes in its internal and external environment. ${ }^{13,21,25,39}$ The evolution of health or disease in the body over time emerges as a result of the nonlinear dynamics underlying inter-connections, inter-relationships, and interactions of the parts that make up the whole. ${ }^{37}$ Functional links between the parts can change in directionality and linkage strength during adaptation. ${ }^{28,40}$ 

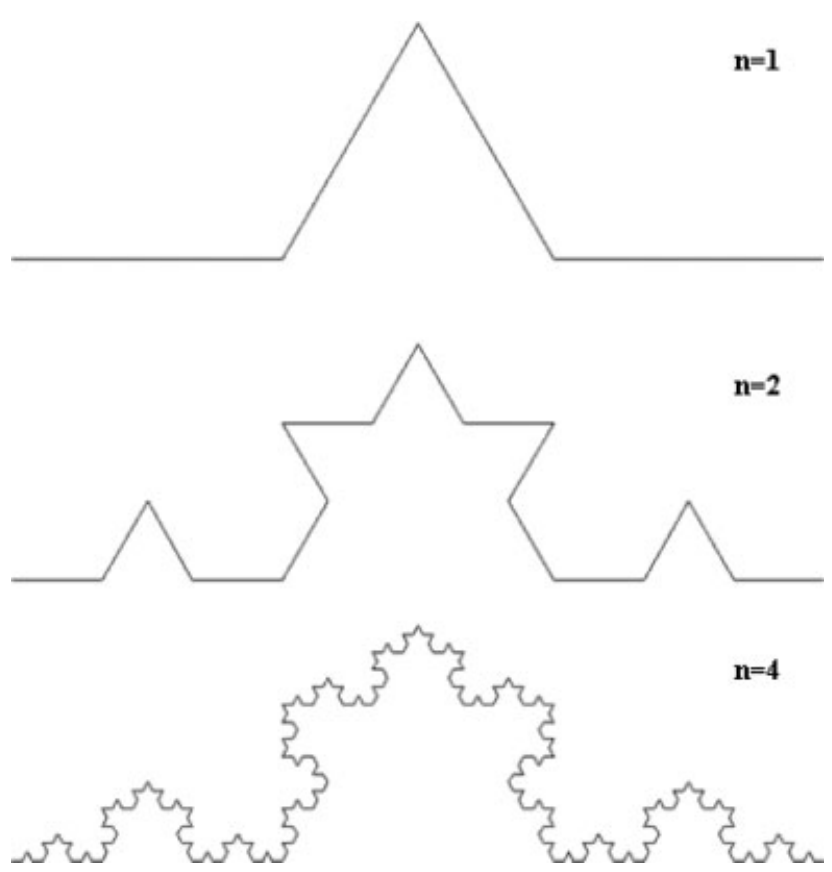

Fig. 1 Self-similarity of fractal structures in a snowflake at different levels of scale. [Used with license: Panther [CC BY-SA 3.0 (http://creativecommons.org/licenses/by-sa/3.0/)].

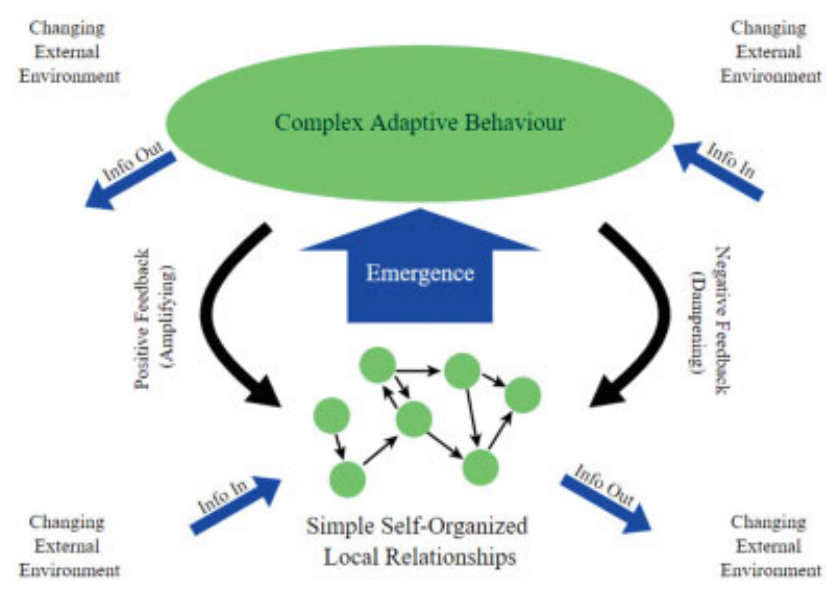

Fig. 2 Complex adaptive system interactivity diagram. [Used with Creative Commons license: https://commons.wikimedia.org/wiki/ File:Complex_adaptive_system.svg]

Disease and aging can reduce systemic complexity of an organism. ${ }^{41}$ In developing diseases such as cancer, the process engages the complex signaling networks or inter-connected intracellular and extracellular pathways of the body as a complex adaptive system/network. ${ }^{28,34,42-44}$ In disease, the body is an open, self-organized complex adaptive system that is out of equilibrium as a consequence of its responses to environmental stressors. Consequently, the body generates patterns of symptoms that are emergent, indirect results of the overall disease process. ${ }^{25,45,46}$

Restoration of healthier complexity and resilience to stressors is a therapeutic goal in this context. ${ }^{25,47}$ It is important to intervene in the non-linear dynamics of CAS at just the right time. That is, the well-timed intervention can interrupt the disease dynamics and trigger a self-organized criticality shift in the state of CAS functioning, allowing the system to restabilize over time into a healthier complex dynamical state. ${ }^{45}$

Initial complexity treatment studies in conventional medical research focused on carefully timing certain electrophysiological interventions to interrupt the dysfunctional nonlinear dynamics of epileptic or cardiac disease in the body. ${ }^{25,48,49}$ Similarly, in homeopathy, properly timing each simillimum medicine dose is also important. ${ }^{35,50}$ It is counterproductive to repeat a medicine too early or too late in shaping the homeopathic healing response of the organism as a whole ${ }^{51}$ back toward health. ${ }^{50}$

In homeopathy, timing matters. For example, in clinical practice, practitioners space out repeat doses of a medicine in time by waiting until symptom improvements from the last dose plateau or begin to relapse. ${ }^{50,52}$ Re-dosing too soon may imprint unwanted medicine-relevant symptoms on the state of the organism for an extended period of time. ${ }^{50}$

\section{The Interface between the Homeopathic Medicine and the Body: Endogenous Signal Amplification Processes}

In a complexity model for homeopathic healing, bodily sensory nervous systems for olfaction, taste or touch detect the signal, ${ }^{53-56}$ and endogenous non-linear amplification mechanisms, ${ }^{18}$ including stochastic resonance, time-dependent sensitization (TDS) in the brain, and hormesis heighten medicine information as a discrete signal and propagate a growing multi-system response. ${ }^{18,56-58}$

All of these non-linear amplification processes require interaction of the treatment with a complex adaptive system to occur. The "treatment" medicine in homeopathy would constitute a biologically detectable, low-intensity discrete input of environmental information that conveys an individually salient danger or damage signal similar to the preexisting disease and triggers endogenous adaptive defense responses in biological networks.

For example, stochastic resonance ${ }^{59}$ is the amplification of a weak signal (cf., medicine information as a small magnitude stressor signal) by a larger band of noise that contains within it the frequency of the stressor signal (cf., emergent disease pattern from the internal environment ${ }^{60}$ ). In animals from rodents to crayfish, sensory systems use stochastic resonance to detect, amplify, and distinguish salient but weak predator danger stimuli (olfactory receptors in rodents or mechanoreceptors in crayfish) from random noise in the external environment. Torres and Ruiz first suggested that stochastic resonance might help amplify an individual's response to a correctly matched homeopathic medicine. ${ }^{57}$

Time-dependent sensitization is another endogenous amplification mechanism observed in CAS. TDS involves the progressive increase in the size of the response within the same recipient to repeated, intermittent "dosing" of small or weak stimuli (i.e., electrical, biochemical, immune, pharmacological, or stressful in nature), simply by the passage of time between exposures. ${ }^{61}$ The signal input magnitude per se can remain small. It is the endogenous adaptive response that grows over time. 
As a result, in TDS, any stimulus perceived or experienced by the organism as a warning of future or past danger or threat will later elicit a much larger bio-behavioral response than it did on first exposure. Thus, if a simillimum medicine captures a small complex informational pattern that resonates in frequency with the emergent body electromagnetic "noise" in the system from the cumulative history and current state of the organism, ${ }^{56}$ the response could be amplified, up to biological limits. ${ }^{62}$

At physiological limits in TDS, however, the direction of change within the same system reverses itself and shifts in the opposite direction: that is, it oscillates from the direction of the original response or current state. ${ }^{62}$ Different classes of stimuli/stressors can cross-sensitize with one another. ${ }^{63,64}$ Once initiated, TDS causes a persistent underlying reactive state of the organism, even a year before the next encounter with the same or a cross-sensitized stimulus/stressor.

TDS occurs with repeated homeopathic medicine dosing. In homeopathy, Bell et al demonstrated that repeated intermittent dose sniffs of individualized medicine versus placebo initiate TDS of spectral EEG responses to subsequent exposures, even when (1) every dose is placed below-not in-the nose and (2) the next dose is more dilute (but also homeopathically more succussed). ${ }^{54}$ Dependent upon the history and state of the organism, repeated subsequent placebocontrolled sniffs of the "same" verum medicine can also evoke directional reversals and/or variations in direction and magnitude of the spectral EEG response patterns. ${ }^{53,65}$

Finally, hormesis is a non-linear (bi-directional) adaptive dose-response phenomenon in a complex adaptive system to interact with a low intensity (weak) or low-dose environmental agent or stressor (including biological, chemical, physical, electromagnetic, and/or psychosocial types of stressors). Hormesis involves low-dose stimulation versus high-dose inhibition or toxicity of physiological and biochemical functions. ${ }^{66-69}$ Consistent with the phenomenology of hormesis, at least three different research groups have shown that various homeopathically prepared medicines at different potencies can stimulate hormetic responses in living cells. ${ }^{70-75}$

With hormesis, the adaptive processes manifest as a complex non-linear dynamical evolving pattern of multisystem and global symptom changes, occurring across the network biology and behavior of the individual recipient. ${ }^{50,52}$ In living systems, these endogenous amplification mechanisms all require interaction of the salient weak (low level) medicine signal information with a complex adaptive system. $^{59,61,68,69,76}$

\section{Summary and Discussion}

Complexity is a dynamical state poised between excessive order and chaos. Adaptations in a living system are all in the service of optimizing the individual's fitness as CAS to survive in an environment that includes encounters with ever-changing larger and smaller stressors. When the adaptations are successful, healing from disease emerges and evolves over time. Resilience to future environmental stressors results.
The potential disease damage/danger signal properties of the correct medicine serve as a salient environmental stressor (see Part 2). The danger signal properties of the simillimum emerge from signaling sensory and/or immune systems to activate body defenses against the low-dose homeopathic medicine information (i.e., an individualized, quantitatively low-dose form of the current disease state of the person-see Part 2 for more detailed discussion).

The implication is that advanced treatment strategies, such as homeopathic simillimum medicine dosing, will also modulate the inter-relationships and interactions of endogenous biological signaling networks and gene expression, a hypothesis supported by studies of certain homeopathic medicines in animal or cellular models for cancer. ${ }^{44,51,77-79}$

If the system is already diseased in some way, it is at or close to its physiological limits (cf., TDS and oscillation). ${ }^{61,62,80,81}$ The body will potentially exhibit transient aggravation up to its physiological limits and then reverse its direction of change back from disease toward a healthier degree of complexity, following the arrival of a low-dose, hormetic salient stimulus to do so. ${ }^{17,35}$

Additional considerations include evidence that (1) endogenous non-linear amplification processes include stochastic resonance, hormesis, and/or TDS; (2) nanostructures, including but not limited to $\mathrm{DNA}^{82,83}$ or miRNA, ${ }^{84}$ can generate weak electromagnetic and/or nano-scale biological signals that stimulate changes in nearby bystander cell biological systems. ${ }^{83,85-87}$ Biological systems are capable of amplifying signals from weak electromagnetic fields. ${ }^{88}$

The correct medicine and living system recipient require communication of an individually relevant "message" 25 or information pattern at their interface. Sensory detection, ${ }^{53,56,65}$ endogenous non-linear cell-to-cell communication, ${ }^{77,87,89-95}$ and non-linear amplification processes ${ }^{18,54}$ in the body engage the inter-connected cells and sub-systems that comprise the body. ${ }^{45}$ The body as an inter-connected emergent network of cells and sub-systems-not the direct effects of the medicine-

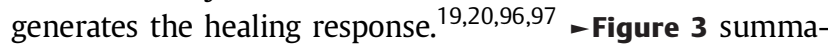
rizes the proposed flow of events.

In homeopathy, the recipient complex adaptive system manifests symptoms as a reflection of the cumulative and interactive emergent effects that past stressors of all categories (biological, chemical, physical, and psychosocial) and intensities have induced in the individual. ${ }^{26,98-101}$ Given a low dose of the correctly chosen homeopathic medicine similar to the current state (i.e., individual's emergent symptom pattern with its associated biology), ${ }^{46}$ systemic healing evolves to strengthen the network and its inter-connected parts against similar existing and future stressors. ${ }^{45}$ The system may alter the links and/or the strength of links between different parts of its network during its stressadaptive process. ${ }^{19,20,28,34,40}$ Improved systemic resilience to current and future stressors is the overall result. ${ }^{45}$

Future research should involve borrowing from existing and emerging methods for the study of (1) non-linear dynamics, (2) self-organization and emergence, and (3) self-similarity. In clinical trials, evaluating both global (overall health ratings) and local (expression of symptoms in specific 


\section{From Homeopathic Manufacturing to Hormetic Healing}

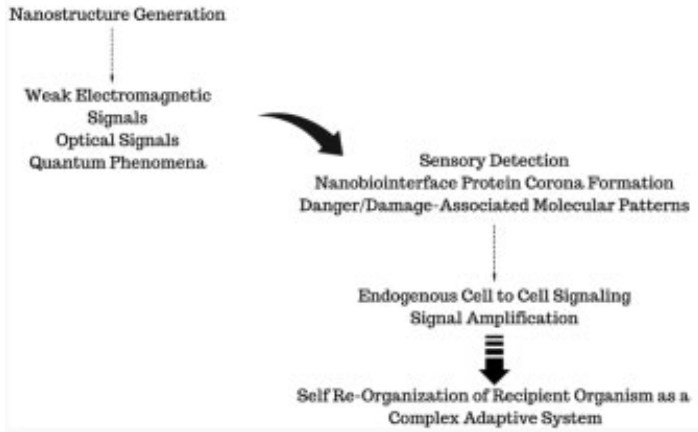

Fig. 3 Overall complexity-based model for homeopathic healing. In this model, once the quantitatively low dose of the homeopathic simillimum medicine in potency interacts with the recipient's sensory and/or immune systems (including the cell danger/damage defense response pathways), the endogenous biology of the organism takes over the healing process as a type of hormesis. The events bring about non-linear adaptive changes that amplify the response to the information of the simillimum and reverse the current disease state that was present at the time of medicine administration (hormesis). Systemic healing further evolves over time via non-linear adaptive changes in biological function across the functional interactive networks of the living system. [Content is original to the author]

organs) states with appropriate outcome measures is important to capture systemic outcomes. ${ }^{102}$

This also means adopting research technologies and analytical methods that can objectively document existence of and changes in the complexity of non-linear modulation of patient physiology: for example, in sleep and waking $\mathrm{EEG}^{17}$ and/or heart rate variability and/or spectroscopy of blood patterns in health and disease. ${ }^{103,104}$

\section{Conclusions}

The body as a complex adaptive system has the capacity for functional self-reorganization, emergence, and multi-scale self-similarity over global (overall health and wellbeing) and local (organ) levels of organization. These features are the key for future biological research on the systemic healing that evolves over time during individualized homeopathic treatment. Complexity is a relevant scientific perspective for understanding the nature of the non-linear healing processes that the homeopathic simillimum can initiate.

In Part 2 of this paper synthesizing available evidence, we shall explore the complex-system nature of homeopathic medicines themselves, during manufacturing and upon administration, in generating the individually salient signal to trigger adaptive healing responses in the biology of a complex adaptive system.

\section{Highlights}

- Living systems are self-organized complex adaptive systems (CAS): that is, networks of inter-connected and interactive parts that manifest healthy or diseased states.

- The simillimum medicine conveys a low-intensity, individually salient environmental danger signal (infor- mation that captures a low-dose version of the preexisting disease pattern) to the sensory and cell defense response networks of the body and thereby initiates the adaptive systemic phenomenon of hormesis.

- In turn, endogenous cell-to-cell signaling pathways transduce and amplify the low-intensity homeopathic information throughout the overall CAS, mobilizing adaptive self-organized changes to improve stress resistance, resilience, and fitness for survival.

- Endogenous signal amplification mechanisms include stochastic resonance, time-dependent sensitization and hormesis.

- The latter two mechanisms can generate directional reversal of symptom pattern expression as a function, respectively, of the initial state of the individual recipient and of the quantitatively low dose of the medicine as a hormetin.

- Consequently, the correct medicine (simillimum) initiates a system-wide non-linear homeopathic healing process carried through the internal dynamics of the body sub-systems/networks, rather than by a direct local pharmacological mechanism of the homeopathic medicine.

Funding
None.

Conflict of Interest

Dr. Bell is a consultant to Standard Homeopathic/Hyland's Inc., a US-based manufacturer of homeopathic medicines. The company did not provide financial support for this paper.

\section{References}

1 Bell IR, Baldwin CM, Schwartz GER. Translating a nonlinear systems theory model for homeopathy into empirical tests. Altern Ther Health Med 2002;8:58-66

2 Bellavite P. Complexity science and homeopathy: a synthetic overview. Homeopathy 2003;92:203-212

3 Bellavite P, Olioso D, Marzotto M, Moratti E, Conforti A. A dynamic network model of the similia principle. Complement Ther Med 2013;21:750-761

4 Camazine S, Deneubourg JL, Franks NR, Sneyd J, Theraulaz G, Bonabeau E. Self-Organization in Biological Systems. Princeton, NJ: Princeton University Press; 2003

5 Meessen A. Water memory due to chains of nano-pearls. J Mod Phys 2018;9:2657-2724

6 Baumgartner S, Doesburg P, Scherr C, Andersen JO. Development of a biocrystallisation assay for examining effects of homeopathic preparations using cress seedlings. Evid Based Complement Alternat Med 2012;2012:125945

7 Kokornaczyk MO, Baumgartner S, Betti L. Polycrystalline structures formed in evaporating droplets as a parameter to test the action of Zincum metallicum 30c in a wheat seed model. Homeopathy 2016;105:173-179

8 Elia V, Marrari LA, Napoli E. Aqueous nanostructures in water induced by electromagnetic fields emitted by EDS. J Therm Anal Calorim 2012;107:843-851

9 Elia V, Napoli E. Dissipative structures in extremely diluted solutions of homeopathic medicines: a molecular model based 
on physico-chemical and gravimetric evidences. Int J Des Nat Ecodyn 2010;5:39-48

10 Germano R. Water's quantum structures and life. Electromagn Biol Med 2015;34:133-137

11 Bell IR, Koithan M. Models for the study of whole systems. Integr Cancer Ther 2006;5:293-307

12 Bell IR, Koithan M, Pincus D. Methodological implications of nonlinear dynamical systems models for whole systems of complementary and alternative medicine. Forsch Komplement Med 2012;19:15-21

13 Koithan M, Bell IR, Niemeyer K, Pincus D. A complex systems science perspective for whole systems of CAM research. Forsch Komplementarmed Klass Naturheilkd 2012;19:7-14

14 Ritenbaugh C, Verhoef M, Fleishman S, Boon H, Leis A. Whole systems research: a discipline for studying complementary and alternative medicine. Altern Ther Health Med 2003;9:32-36

15 Bellavite P, Signorini A. The Emerging Science of Homeopathy. Complexity, Biodynamics, and Nanopharmacology. 2nd ed. Berkeley: North Atlantic Books; 2002:408

16 Bellavite P, Signorini A, Marzotto M, Moratti E, Bonafini C, Olioso D. Cell sensitivity, non-linearity and inverse effects. Homeopathy 2015;104:139-160

17 Bell IR, Howerter A, Jackson N, Aickin M, Bootzin RR, Brooks AJ. Nonlinear dynamical systems effects of homeopathic remedies on multiscale entropy and correlation dimension of slow wave sleep EEG in young adults with histories of coffee-induced insomnia. Homeopathy 2012;101:182-192

18 Bell IR, Sarter B, Koithan M, Standish LJ, Banerji P, Banerji P. Nonlinear response amplification mechanisms for low doses of natural product nanomedicines: dynamical interactions with the recipient complex adaptive system. J Nanomed Nanotechnol 2013;4:179

19 Bell IR, Schwartz GE. Adaptive network nanomedicine: an integrated model for homeopathic medicine. Front Biosci (Schol Ed) 2013;5:685-708

20 Bell IR, Schwartz GE, Frye J, Sarter B, Standish LJ. Extending the adaptive network nanomedicine model for homeopathic medicine: nanostructures as salient cell danger signals for adaptation. Nanoscience and Technology Open Access 2015; 2:1-22

21 Baffy G, Loscalzo J. Complexity and network dynamics in physiological adaptation: an integrated view. Physiol Behav 2014; 131:49-56

22 Barabási AL, Gulbahce N, Loscalzo J. Network medicine: a network-based approach to human disease. Nat Rev Genet 2011;12:56-68

23 Bewick S, Yang R, Zhang M. Complex mathematical models of biology at the nanoscale. Wiley Interdiscip Rev Nanomed Nanobiotechnol 2009;1:650-659

24 Brizhik L, Foletti A. Nonlinear quantum phenomena and biophysical aspects of complexity related to health and disease. J Biol Regul Homeost Agents 2014;28:357-366

25 Coffey DS. Self-organization, complexity and chaos: the new biology for medicine. Nat Med 1998;4:882-885

26 McEwen BS. Biomarkers for assessing population and individual health and disease related to stress and adaptation. Metabolism 2015;64:S2-S10

27 Mitchell M. Complexity: A Guided Tour. New York, NY: Oxford University Press; 2009

28 Szalay MS, Kovács IA, Korcsmáros T, Böde C, Csermely P. Stressinduced rearrangements of cellular networks: Consequences for protection and drug design. FEBS Lett 2007;581:3675-3680

29 Goldbeter A. Dissipative structures in biological systems: bistability, oscillations, spatial patterns and waves. Philosophical transactions Series A, Mathematical, physical, and engineering sciences 2018:376

30 Wedlich-Söldner R, Betz T. Self-organization: the fundament of cell biology. Philos Trans R Soc Lond B Biol Sci 2018;373:373
31 Brien SB, Harrison H, Daniels J, Lewith G. Monitoring improvement in health during homeopathic intervention. Development of an assessment tool based on Hering's Law of Cure: the Hering's Law Assessment Tool (HELAT). Homeopathy 2012;101:28-37

32 Vázquez A, Dobrin R, Sergi D, Eckmann JP, Oltvai ZN, Barabási AL. The topological relationship between the large-scale attributes and local interaction patterns of complex networks. Proc Natl Acad Sci U S A 2004;101:17940-17945

33 Korcsmáros T, Szalay MS, Böde C, Kovács IA, Csermely P. How to design multi-target drugs. Expert Opin Drug Dev 2007; 2:799-808

34 Csermely P, Agoston V, Pongor S. The efficiency of multi-target drugs: the network approach might help drug design. Trends Pharmacol Sci 2005;26:178-182

35 Bertani S, Lussignoli S, Andrioli G, Bellavite P, Conforti A. Dual effects of a homeopathic mineral complex on carrageenaninduced oedema in rats. Br Homeopath J 1999;88:101-105

36 Czaplicka A, Holyst JA, Sloot PM. Noise enhances information transfer in hierarchical networks. Sci Rep 2013;3:1223

37 Lopes FM, Cesar RM, Costa LdaF. Gene expression complex networks: synthesis, identification, and analysis. JComput Biol 2011;18:1353-1367

38 Vidal M, Cusick ME, Barabási AL. Interactome networks and human disease. Cell 2011;144:986-998

39 Ten Broeke GA, van Voorn GA, Ligtenberg A, Molenaar J. Resilience through adaptation. PLoS One 2017;12:e0171833

40 Csermely P. Weak Links: Stabilizers of Complex Systems from Proteins to Social Networks. Berlin: Springer-Verlag; 2006

41 Lipsitz LA, Goldberger AL. Loss of 'complexity' and aging. Potential applications of fractals and chaos theory to senescence. JAMA 1992;267:1806-1809

42 Seely AJ, Christou NV. Multiple organ dysfunction syndrome: exploring the paradigm of complex nonlinear systems. Crit Care Med 2000;28:2193-2200

43 Korcsmáros T, Farkas IJ, Szalay MS, et al. Uniformly curated signaling pathways reveal tissue-specific cross-talks and support drug target discovery. Bioinformatics 2010;26: 2042-2050

44 Csermely P, Korcsmáros T, Nussinov R. Intracellular and intercellular signaling networks in cancer initiation, development and precision anti-cancer therapy: RAS acts as contextual signaling hub. Semin Cell Dev Biol 2016;58:55-59

45 Pincus D, Metten A. Nonlinear dynamics in biopsychosocial resilience. Nonlinear Dyn Psychol Life Sci 2010;14:353-380

46 Manzalini A, Galeazzi B. Explaining homeopathy with quantum electrodynamics. Homeopathy 2019;108:169-176

47 Ahn AC, Nahin RL, Calabrese C, et al. Applying principles from complex systems to studying the efficacy of CAM therapies. JAltern Complement Med 2010;16:1015-1022

48 Garfinkel A, Spano ML, Ditto WL, Weiss JN. Controlling cardiac chaos. Science 1992;257:1230-1235

49 Schiff SJ, Jerger K, Duong DH, Chang T, Spano ML, Ditto WL. Controlling chaos in the brain. Nature 1994;370:615-620

50 Vithoulkas G. The Science of Homeopathy. New York, NY: Grove Weidenfeld; 1980

51 Bell IR, Sarter B, Koithan M, et al. Integrative nanomedicine: treating cancer with nanoscale natural products. Glob Adv Health Med 2014;3:36-53

52 Oberbaum M, Singer SR, Vithoulkas G. The colour of the homeopathic improvement: the multidimensional nature of the response to homeopathic therapy. Homeopathy 2005;94:196-199

53 Bell IR, Brooks AJ, Howerter A, Jackson N, Schwartz GE. Shortterm effects of repeated olfactory administration of homeopathic sulphur or pulsatilla on electroencephalographic alpha power in healthy young adults. Homeopathy 2011;100:203-211

54 Bell IR, Lewis DA II, Lewis SE, et al. EEG alpha sensitization in individualized homeopathic treatment of fibromyalgia. Int $\mathrm{J}$ Neurosci 2004;114:1195-1220 
55 Courtens F, Demangeat JL, Benabdallah M. Could the olfactory system be a target for homeopathic remedies as nanomedicines? JAltern Complement Med 2018;24:1032-1038

56 Shahabi S, Kasariyans A, Noorbakhsh F. Like cures like: a neuroimmunological model based on electromagnetic resonance. Electromagn Biol Med 2013;32:508-526

57 Torres JL, Ruiz MAG. Stochastic resonance and the homeopathic effect. Br Homeopath J 1996;85:134-140

58 Moss F, Ward LM, Sannita WG. Stochastic resonance and sensory information processing: a tutorial and review of application. Clin Neurophysiol 2004;115:267-281

59 McDonnell MD, Abbott D. What is stochastic resonance? Definitions, misconceptions, debates, and its relevance to biology. PLOS Comput Biol 2009;5:e1000348

60 Hackshaw KV, Aykas DP, Sigurdson GT, et al. Metabolic fingerprinting for diagnosis of fibromyalgia and other rheumatologic disorders. JBiol Chem 2019;294:2555-2568

61 Antelman SM, Levine J, Gershon S. Time-dependent sensitization: the odyssey of a scientific heresy from the laboratory to the door of the clinic. Mol Psychiatry 2000;5:350-356

62 Antelman SM, Caggiula AR. Oscillation follows drug sensitization: implications. Crit Rev Neurobiol 1996;10:101-117

63 Sorg BA, Bailie TM, Tschirgi ML, Li N, Wu WR. Exposure to repeated low-level formaldehyde in rats increases basal corticosterone levels and enhances the corticosterone response to subsequent formaldehyde. Brain Res 2001;898:314-320

64 Wiegant FA, Spieker N, van Wijk R. Stressor-specific enhancement of hsp induction by low doses of stressors in conditions of self- and cross-sensitization. Toxicology 1998;127:107-119

65 Bell IR, Brooks AJ, Howerter A, Jackson N, Schwartz GE. Acute electroencephalographic effects from repeated olfactory administration of homeopathic remedies in individuals with selfreported chemical sensitivity. Altern Ther Health Med 2013; 19:46-57

66 Calabrese EJ. Hormetic mechanisms. Crit Rev Toxicol 2013; 43:580-606

67 Dei A, Bernardini S. Hormetic effects of extremely diluted solutions on gene expression. Homeopathy 2015;104:116-122

68 Iavicoli I, Leso V, Fontana L, Calabrese EJ. Nanoparticle exposure and hormetic dose-responses: an update. Int J Mol Sci 2018; 19:19

69 Iavicoli I, Calabrese EJ, Nascarella MA. Exposure to nanoparticles and hormesis. Dose Response 2010;8:501-517

70 Van Wijk R, Wiegant FA. Postconditioning hormesis and the homeopathic Similia principle: molecular aspects. Hum Exp Toxicol 2010;29:561-565

71 Wiegant FA, de Poot SA, Boers-Trilles VE, Schreij AM. Hormesis and cellular quality control: a possible explanation for the molecular mechanisms that underlie the benefits of mild stress. Dose Response 2012;11:413-430

72 Wiegant FA, Prins HA, Van Wijk R. Postconditioning hormesis put in perspective: an overview of experimental and clinical studies. Dose Response 2011;9:209-224

73 Van Wijk R, Wiegant FA. Postconditioning hormesis and the similia principle. Front Biosci (Elite Ed) 2011;3:1128-1138

74 Chikramane PS, Suresh AK, Kane SG, Bellare JR. Metal nanoparticle induced hormetic activation: a novel mechanism of homeopathic medicines. Homeopathy 2017;106:135-144

75 Malarczyk E, Pazdzioch-Czochra M, Grąz M, Kochmańska-Rdest J, Jarosz-Wilkołazka A. Nonlinear changes in the activity of the oxygen-dependent demethylase system in Rhodococcus erythropolis cells in the presence of low and very low doses of formaldehyde. Nonlinear Biomed Phys 2011;5:9

76 Calabrese EJ, Mattson MP. Hormesis provides a generalized quantitative estimate of biological plasticity. JCell Commun Signal 2011;5:25-38

77 Khuda-Bukhsh AR, Bhattacharyya SS, Paul S, Dutta S, Boujedaini $\mathrm{N}$, Belon P. Modulation of signal proteins: a plausible mechanism to explain how a potentized drug Secale Cor 30C diluted beyond Avogadro's limit combats skin papilloma in mice. Evid Based Complement Alternat Med 2011;2011:286320

78 Saha S, Hossain DM, Mukherjee S, et al. Calcarea carbonica induces apoptosis in cancer cells in p53-dependent manner via an immuno-modulatory circuit. BMC Complement Altern Med 2013;13:230

79 Saha S, Bhattacharjee P, Guha D, et al. Sulphur alters NFkB-p300 cross-talk in favour of p53-p300 to induce apoptosis in nonsmall cell lung carcinoma. Int J Oncol 2015;47:573-582

80 Antelman SM, Caggiula AR, Gershon S, et al. Stressor-induced oscillation. A possible model of the bidirectional symptoms in PTSD. Ann N Y Acad Sci 1997;821:296-304

81 Antelman SM, Eichler AJ, Black CA, Kocan D. Interchangeability of stress and amphetamine in sensitization. Science 1980; 207:329-331

82 Montagnier L, Aïssa J, Ferris S, Montagnier JL, Lavallée C. Electromagnetic signals are produced by aqueous nanostructures derived from bacterial DNA sequences. Interdiscip Sci 2009; 1:81-90

83 Montagnier L, Del Giudice E, Aïssa J, et al. Transduction of DNA information through water and electromagnetic waves. Electromagn Biol Med 2015;34:106-112

84 Al-Mayah A, Bright S, Chapman K, et al. The non-targeted effects of radiation are perpetuated by exosomes. Mutat Res 2015; 772:38-45

85 Le M, Fernandez-Palomo C, McNeill FE, Seymour CB, Rainbow AJ, Mothersill CE. Exosomes are released by bystander cells exposed to radiation-induced biophoton signals: reconciling the mechanisms mediating the bystander effect. PLoS One 2017;12: e0173685

86 Klammer H, Mladenov E, Li F, Iliakis G. Bystander effects as manifestation of intercellular communication of DNA damage and of the cellular oxidative status. Cancer Lett 2015; 356:58-71

87 Eldh M, Ekström K, Valadi H, et al. Exosomes communicate protective messages during oxidative stress; possible role of exosomal shuttle RNA. PLoS One 2010;5:e15353

88 Zhao J, Deng B, Qin Y, et al. Weak electric fields detectability in a noisy neural network. Cogn Neurodyn 2017;11:81-90

89 Bayraktar R, Van Roosbroeck K, Calin GA. Cell-to-cell communication: microRNAs as hormones. Mol Oncol 2017;11: 1673-1686

90 Corrado C, Raimondo S, Chiesi A, Ciccia F, De Leo G, Alessandro R. Exosomes as intercellular signaling organelles involved in health and disease: basic science and clinical applications. Int J Mol Sci 2013;14:5338-5366

91 Couto N, Caja S, Maia J, Strano Moraes MC, Costa-Silva B. Exosomes as emerging players in cancer biology. Biochimie 2018;155:2-10

92 Hosseini HM, Fooladi AA, Nourani MR, Ghanezadeh F. The role of exosomes in infectious diseases. Inflamm Allergy Drug Targets 2013;12:29-37

93 Isola AL, Chen S. Exosomes: the messengers of health and disease. Curr Neuropharmacol 2017;15:157-165

94 Maia J, Caja S, Strano Moraes MC, Couto N, Costa-Silva B. Exosome-based cell-cell communication in the tumor microenvironment. Front Cell Dev Biol 2018;6:18

95 Mathivanan S, Ji H, Simpson RJ. Exosomes: extracellular organelles important in intercellular communication. JProteomics 2010;73:1907-1920

96 Bell IR. Homeopathy as systemic adaptational nanomedicine: the nanoparticle-cross-adaptation-sensitization model. Am J Homeopath Med 2012;105:116-130

97 Bell IR, Koithan M. A model for homeopathic remedy effects: low dose nanoparticles, allostatic cross-adaptation, and time-dependent sensitization in a complex adaptive system. BMC Complement Altern Med 2012;12:191 
98 McEwen BS. Stress, adaptation, and disease. Allostasis and allostatic load. Ann N Y Acad Sci 1998;840:33-44

99 McEwen BS. Interacting mediators of allostasis and allostatic load: towards an understanding of resilience in aging. Metabolism 2003;52:10-16

100 McEwen BS. Protection and damage from acute and chronic stress: allostasis and allostatic overload and relevance to the pathophysiology of psychiatric disorders. Ann N Y Acad Sci 2004;1032:1-7

101 McEwen BS. In pursuit of resilience: stress, epigenetics, and brain plasticity. Ann N Y Acad Sci 2016;1373:56-64
102 Bell IR, Lewis DA II, Schwartz GE, et al. Electroencephalographic cordance patterns distinguish exceptional clinical responders with fibromyalgia to individualized homeopathic medicines. J Altern Complement Med 2004;10:285-299

103 Swapna MS, Shinker SS, Suresh S, Sankararaman S. Raman spectroscopic and fractal analysis of blood samples of dengue fever patients. Biomed Mater Eng 2018;29:787-797

104 Tavakol M, Montazeri A, Naghdabadi R, et al. Disease-related metabolites affect protein-nanoparticle interactions. Nanoscale 2018;10:7108-7115 